\title{
Histopatologia da lâmina própria do seio maxilar na rinossinusite crônica
}

\author{
Sabrina Maria de Castro Sarreta', João Vicente \\ Dorgam¹, Bruno Beltrão de Souza', Maria Dolores \\ Seabra Ferreira2, Valder Rodrigues de $\mathrm{Melo}^{3}$, \\ WilmaT. Anselmo-Lima ${ }^{4}$
}

\section{Histopathology of maxillary sinus lamina propria in chronic rhinosinusitis}

Resumo / Summary

\begin{abstract}
A rinossinusite crônica é definida de modo simplificado como uma inflamação crônica da mucosa nasossinusal. Objetivo: Na tentativa de entender o porquê das fal has terapêuticas. Forma de estudo: Caso-controle. Material e método: Decidimos estudar as alterações inflamatórias ultraestruturais encontradas na lâmina própria do seio maxilar de 13 pacientes portadores de rinossinusite crônica (RSC) e polipose nasossinusal (PNS), submetidos a tratamento cirúrgico. Biópsias da parede súpero-lateral do seio maxilar desses pacientes foram colhidas durante 0 ato operatório e, após preparação, observadas através de microscopia eletrônica de transmissão. Resultado: $\mathrm{Na}$ análise dos dados obtidos, observou-se cinco padrões de resposta inflamatória nas lâminas próprias estudadas inflamatório crônico. Processo inflamatório agudo - 1 caso; processo inflamatório não agudo e não crônico - 5 casos; processo inflamatório crônico - 2 casos; processo inflamatório desorganizado - 4 casos; processo inflamatório indeterminado - 1 caso. Concluindo, a análise dos resultados mostrou que a lâmina própria do seio maxilar desses pacientes esteve infiltrada por células inflamatórias, sem predomínio específico de qualquer elemento celular. Elementos glandulares não foram observados nos casos estudados e a fibrose foi notada em quase metade deles, com intensidade variada e localização preferencial logo abaixo do epitélio. Conclusão: Na situação vista, o processo inflamatório não seguiu as etapas normais de evolução, mostrou marcante desorganização do processo inflamatório, dificuldade em caminhar até a resolução do quadro, acompanhando a mesma dificuldade de resolução clínica nos pacientes.
\end{abstract}

\author{
Palavras-chave: rinossinusite crônica, \\ cirurgia, histopatologia, mucosa. \\ Key words: chronic rinossinusitis, \\ histopatology, mucosa, surgery.
}

hronic rhinosinusitis is defined in a simplified manner as chronic inflammation of the rhinosinusal mucosa. Aim: In an attempt to understand the reason for treatment failure. Study design: Case-control. Material and method: We decided to study the ultrastructural inflammatory changes detected in the lamina propria of the maxillary sinus of 13 patients with chronic rhinosinusitis and nasosinusal polyposis submitted to surgical treatment. Biopsies of the superolateral wall of the maxillary sinus were obtained from these patients during the surgical act and, after preparation, were observed by transmission electron microscopy. Results: Analysis of the data obtained showed five patterns of inflammatory response in the lamina propria studied. Acute inflammatory process - 1 case; non-acute and nonchronic inflammatory process - 5 cases; chronic inflammatory process - 2 cases; disorganized inflammatory process - 4 cases; indeterminate inflammatory process - 1 case. Analysis of the results showed that the lamina propria of the maxillary sinus of these patients was infiltrated with inflammatory cells without the predominance of any particular cell element. Glandular elements were not observed in the cases studied and fibrosis was noted in almost half of them, of varying intensity and preferentially localized immediately below the epithelium. Conclusion: In the situation observed the inflammatory process did not follow the normal stages of evolution and showed marked disorganization, with difficulty in progressing to resolution of the picture, thus explaining the difficulties of patients refractory to clinical and surgical treatment.

\footnotetext{
Pós-Graduandos, Nível Mestrado do Departamento de Oftalmologia, Otorrinolaringologia e Cirurgia de Cabeça e Pescoço da FMRP-USP

${ }^{2}$ Técnica do Laboratório de Microscopia Eletrônica do Departamento de Biologia Celular e Molecular e Bioagentes Patogênicos. 3 Professor Doutor do Departamento de Cirurgia e Anatomia da FMRP-USP.

${ }^{4}$ Professora Associada do Departamento de Oftalmologia, O torrinolaringologia e Cirurgia de Cabeça e Pescoço da FMRP-USP. Apresentado no II Congresso Triológico de Otorrinolaringologia da SBORL-Goiânia-2001. Endereço para Correspondência: Profa. Dra. Wilma T. Anselmo-Lima - Departamento de Oftalmologia e Otorrinolaringologia e Cirurgia de Cabeça e Pescoço do HCFMRP-USP Avenida Bandeirantes $n .03900$ 14049-900 Ribeirão Preto SP Tel (0xx16) 602-2862 - Fax (0xx16) 602-2860.

Artigo recebido em 10 de abril de 2003. Artigo aceito em 15 de janeiro de 2004.
} 


\section{INTRODUÇÃO}

A RSC associada à PNS é uma doença que prejudica a qualidade de vida de milhões de pessoas em todo o mundo. Apesar do avanço obtido nas áreas clínica e de pesquisa, sua exata fisiopatologia ainda é desconhecida. Inflamações são reações dos tecidos conjuntivos vascularizados, caracterizadas morfologicamente pela saída de líquido e de células do sangue para o interstício. 0 elemento morfológico essencial da inflamação é o exsudato celular. Agentes agressores físicos, químicos ou biológicos podem desencadear o processo inflamatório. Esse processo é um fenômeno dinâmico, portanto, seu aspecto morfológico se modifica com o tempo ${ }^{1}$.

0 agente flogógeno age sobre os tecidos e induz a liberação de substâncias denominadas mediadores, que atuam nos receptores existentes nas células da microcirculação e nos leucócitos, produzindo alterações hemodinâmicas e exsudação de plasma e de células sanguíneas para 0 interstício. A ação do agente inflamatório pode produzir lesão nos tecidos. Quando cessa a ação do agente flogógeno, reduz-se a liberação dos mediadores, a microcirculação recupera o estado hemodinâmico original e o líquido e as células exsudadas voltam à circulação sanguínea geralmente pelos vasos linfáticos. Dependendo da extensão da lesão tecidual e do órgão acometido surgem os fenômenos de cicatrização ou de regeneraçãoํ.

Há agentes inflamatórios que podem manter a inflamação por longo tempo, porque agem repetidamente e são de difícil eliminação ou porque induzem resposta imunitária a seus antígenos. Nessas circunstâncias, a resposta inflamatória persiste em razão da geração continuada de mediadores que estimulam a exsudação celular. Depois de certo tempo, ocorre neoformação conjuntiva e vascular para reparação das lesões destrutivas, enquanto as células do exsudato sofrem diversas alterações. A reação inflamatória toma um curso crônico e pode durar tempo variável, geralmente induzindo lesões progressivas ${ }^{1-3}$

0 processo inflamatório pode ser dividido em etapas ou fases, uma após a outra, mas muitas vezes superpondose durante o desenrolar do processo. Tais etapas seriam: a) irritação; b) alterações vasculares; c) exsudação plasmática e celular; d) lesões degenerativas e necróticas; e) proliferação conjuntiva e vascular reparadora; e, nos casos crônicos, f) modificações das células do exsudato. A capacidade de reparar lesões inflamatórias depende do tipo de inflamação e de elementos genéticos do indivíduo. Nas inflamações crônicas persistentes, os fenômenos de reparação existem ao lado de fenômenos exsudativos, alterativos e produtivos, fazendo parte do processo ${ }^{1}$.

As modificações das células do exsudato após sua migração para o interstício representam os fenômenos produtivos da inflamação. São mais facilmente observáveis nos casos crônicos e geralmente se associam aos fenômenos reparativos ${ }^{1}$.
Entre as células exsudadas, os polimorfonucleares e os eosinófilos têm vida muito curta e, quando chegam ao foco inflamatório, já sofreram todo o processo de diferenciação, razão pela qual morrem poucas horas depois de exsudados. Os linfócitos do foco inflamatório podem sofrer diferenciação. Os linfócitos T podem proliferar e ser ativados adquirindo 0 aspecto morfológico de imunoblastos; os linfócitos $B$ diferenciam-se em plasmócitos, às vezes numerosos em algumas inflamações. Essas transformações indicam que há participação efetiva da resposta imune celular e humoral no tecido inflamado e que esta influencia a evolução das inflamações ${ }^{1}$. Os monócitos acumulam-se no interstício atraídos pelos fatores quimiotáticos e aí são ativados, transformando-se em macrófagos com maior poder fagocitário e microbicida. 0 acúmulo de macrófagos no foco inflamatório se deve à persistência de estímulos quimiotáticos. São os macrófagos que produzem as principais lesões teciduais nas inflamações crônicas, tanto devido à ação lesiva dos radicais livres produzidos e das enzimas excretadas quanto devido à produção de fatores de crescimento para endotélio e fibroblastos, o que induz neoformação conjuntivo-vascular cicatricial ${ }^{1}$.

As células endoteliais encontram-se ativadas nas inflamações crônicas, especialmente naquelas relacionadas com mecanismos imunitários. Em resposta, expõem na membrana moléculas de adesão necessárias à exsudação de leucócitos conforme os estímulos quimiotáticos gerados. Os mastócitos do tecido conjuntivo podem aumentar de número nas inflamações crônicas - por mecanismos desconhecidos - e pouco se sabe sobre seu papel nessas inflamações ${ }^{1-3}$.

O objetivo deste estudo foi a avaliação histológica ultraestrutural da lâmina própria de seio maxilar de pacientes portadores de RSC associada à PNS para melhor compreendermos a evolução do processo inflamatório em tal patologia.

\section{CASUÍSTICA E MÉTODO}

0 grupo de estudo foi composto por treze pacientes portadores de RSC associada à PNS, atendidos no Ambulatório de Rinossinusologia da nossa disciplina. Seis eram do sexo masculino e sete do sexo feminino. A idade variou de onze a setenta e três anos com média de 43,23 anos. 0 grupo controle foi composto de 4 cadáveres submetidos a necropsia pelo Serviço de Verificação de Ó bitos do Departamento de Patologia da F.M.R.P-USP sem história prévia de rinossinusite e com causa mortis não infecciosa. Submetidos à nasofibroscopia não apresentavam alterações anatômicas ou suspeitas de patologia respiratória.

Nesse estudo, aprovado pelo Comitê de Ética em Pesquisa do HCFMRP-USP de acordo com o processo no 1930/97, foram incluídos unicamente os pacientes portadores de RSC associada à PNS, refratária a todo e qualquer 
tratamento clínico, submetidos a tratamento cirúrgico pela mesma equipe de Rinossinusologia. Todos os pacientes apresentavam à TC de seios da face, 50 a 100\% da cavidade dos seios maxilares ocupada por espessamento mucoso e/ ou efusão e/ ou pólipos. 0 comprometimento tomográfico estendia-se aos seios etmoidais, esfenoidais e frontais em graus variados. Foram excluídos pacientes portadores de outras doenças correlacionadas com a PNS, como fibrose cística, discinesia ciliar primária, imunodeficiência, intolerância ao ácido acetil salicílico e asma grave.

A mucosa do seio maxilar foi obtida durante 0 ato operatório, com o paciente sob anestesia geral, no Centro Cirúrgico após limpeza do seio maxilar. Com a abertura do óstio foram retirados secreções, cistos e/ ou pólipos; a biópsia foi realizada na mucosa espessada da parede súpero-lateral com pinça curva de Blakesley-Wilde, preservando ao máximo a porção superior. A amostra foi então entregue para 0 preparo de fixação em uma solução de aldeído glultárico a 3,0\% em tampão Sorensen por 3 a 4 horas. As amostras destinadas ao exame pela microscopia eletrônica de transmissão (MET) foram divididas em fragmentos ainda menores que após serem lavados no tampão foram imersos em uma solução de tetróxido de ósmio a 1,0\% em tampão Sorensen 0,1 Molar por 2 horas em temperatura de 4 graus Celsius. Desidratados, os fragmentos foram infiltrados e incluídos na Resina Araldite 6005, seccionados em um ultramicrótomo (Reichert UltraCut S) na espessura inicial de 0,5 micrômetro e montados em lâminas histológicas. Os cortes assim obtidos eram corados pela solução de azul de toluidina a 1,0\% em bórax e guardados para exame ao microscópio óptico. Feita a análise e seleção dos cortes dos fragmentos para microscopia óptica (MO) os blocos eram reaparados e submetidos ao corte ultra-fino (60-70 nanômetros) que eram recolhidos em grades de cobre, e submetidos a um processo de contrastação pelo acetato de uranila e citratato de chumbo, observados e eletronfotografados em um Microscópio Philips 208 operando à $80 \mathrm{Kv}$ em chapas Kodak 4489 em aumentos variáveis. A lâmina própria do seio maxilar de cada grade foi avaliada quanto às suas características gerais e distribuição da sua celularidade.

Os cortes semifinos corados pelo azul de toluidina serviram de base para o estudo da MO. Com eles foi feita a classificação do tipo epitelial do revestimento mucoso baseado no número de camadas celulares (simples, estratificado ou pseudo-estratificado) e no tipo celular mais superficial (escamoso, colunar). Foram fotomicrografados em um fotomicroscópio Zeiss com objetivas Apo 40 ou PlaApo 63 em iluminação Kohler.

\section{RESULTADOS}

Foram estudados à MET a lâmina própria do seio maxilar de quatro cadáveres, como grupo controle, e de treze pacientes do grupo de estudo. Várias amostras de cada cadáver foram exaustivamente estudadas. A lâmina própria sob a membrana basal delicada estava bastante fina, composta de tecido frouxo, com alguns leucócitos espalhados. Escreveremos e ilustraremos agora os achados de cada paciente do grupo de estudo.

\section{Caso 1}

Processo inflamatório crônico (resposta tardia): Notamos agressão intensa ao tecido, com diversidade e abundância de figuras celulares tendendo a um predomínio mononuclear e ausência de representantes do processo alérgico. Observamos presença de elementos de destruição e limpeza e fibrose da lâmina própria próxima ao epitélio (Figura 1).

\section{Caso 2}

Processo inflamatório indeterminado: Há grande diversidade do quadro, que apresenta áreas em diferentes etapas do processo inflamatório ao lado de áreas normais. O bservamos claramente um achado de fibrose da lâmina própria. Não vemos nenhuma célula do infiltrado inflamatório predominando sobre as outras (Figura 2).

\section{Caso 3}

Processo inflamatório não agudo e não crônico: 0 quadro inflamatório caminha para a cronicidade e resolução do processo, com fibrose presente na lâmina própria. 0 interstício apresenta muitos restos celulares. Não há predomínio de um elemento celular sobre os outros (Figura 3).

\section{Caso 4}

Processo inflamatório agudo: O bserva-se notada dominância de neutrófilos dentre as células inflamatórias, com raros elementos do processo crônico. Foram poucas e discretas as áreas de fibrose vistas nesse caso (Figura 4).

\section{Caso 5}

Processo inflamatório não agudo e não crônico: Encontramos nesse caso eosinófilos em grande quantidade e fibroblastos extremamente ativados. A resposta dos elementos intercelulares aponta para um quadro inflamatório crônico resolvido, enquanto a resposta dos elementos celulares mostra um quadro inflamatório agudo (Figura 5).

\section{Caso 6}

Processo inflamatório não agudo e não crônico: Nesse caso observamos grande diversidade da população celular, sem predomínio de nenhum tipo de célula inflamatória (presença de macrófagos, plasmócitos, raros linfócitos e ausência de neutrófilos) e ausência de organização no interstício. Existe a presença de áreas com restos celulares disseminados alternadas com áreas de população celular escassa (Figura 6). 


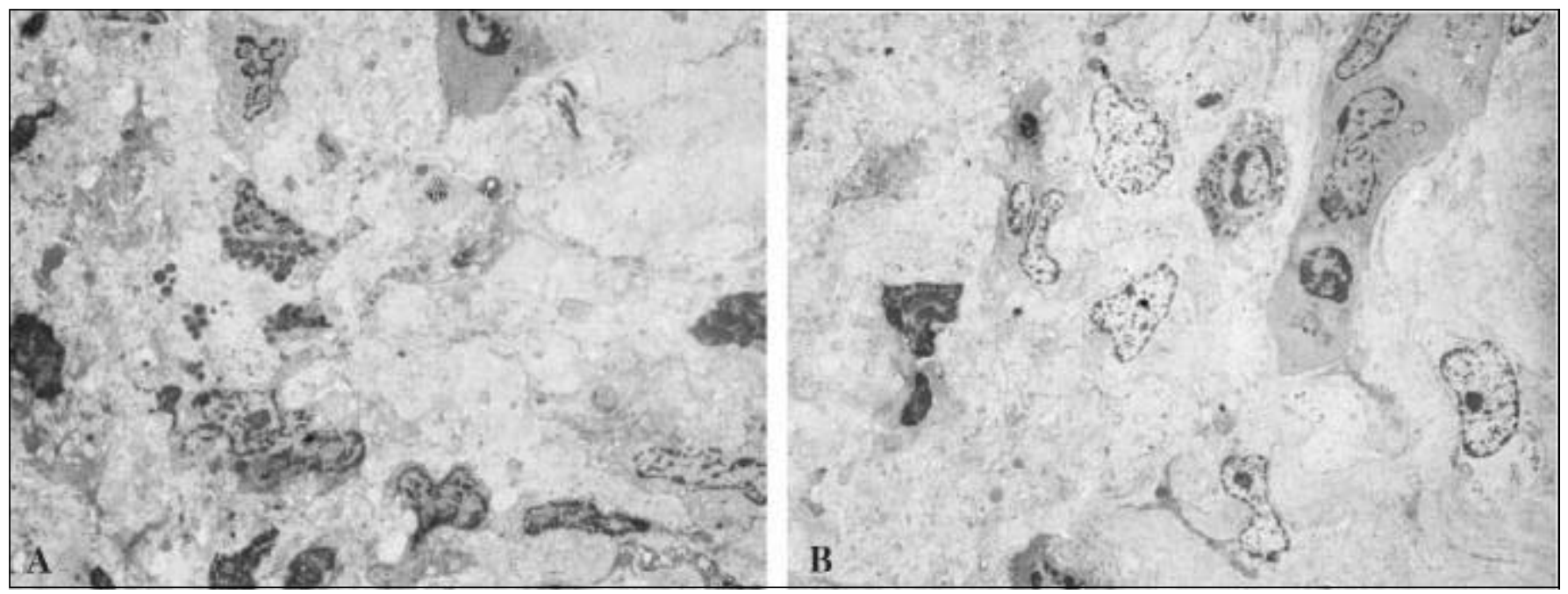

Figura 1: A- Processo inflamatório crônico com predomínio de células mononucleares (2000X). B- Processo inflamatório crônico com presença de fibrose no interstício (2000X).

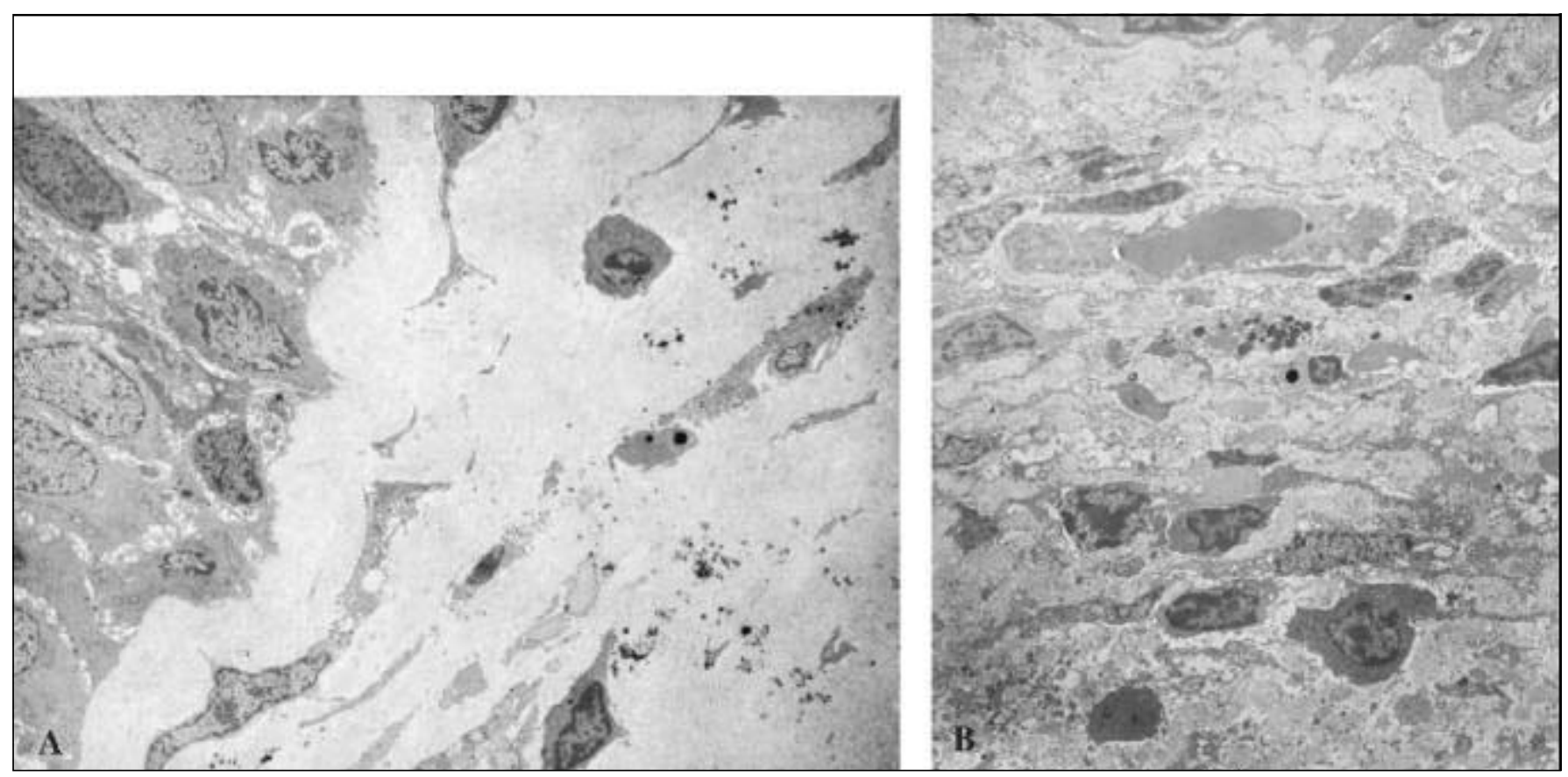

Figura 2: A- Lâmina própria com fibrose intensa e poucos elementos do infiltrado celular inflamatório (2000X). B- Lâmina própria com intenso infiltrado celular inflamatório(2000X).

Caso 7

Processo inflamatório desorganizado (anárquico): Os processos inflamatórios agudo e crônico encontram-se presentes simultaneamente nesse caso. O bserva-se toda a população celular tanto do processo alérgico quanto do processo inflamatório misturadas, sem nenhuma célula predominante (Figura 7).

\section{Caso 8}

Processo inflamatório não agudo e não crônico: $\mathrm{Ob}$ servamos notada diversidade celular, com presença de elementos agudos e crônicos do processo inflamatório. Não houve predomínio de um elemento celular sobre os outros. A área da lâmina própria próxima ao epitélio encontra-se intensamente colágena (Figura 8). 


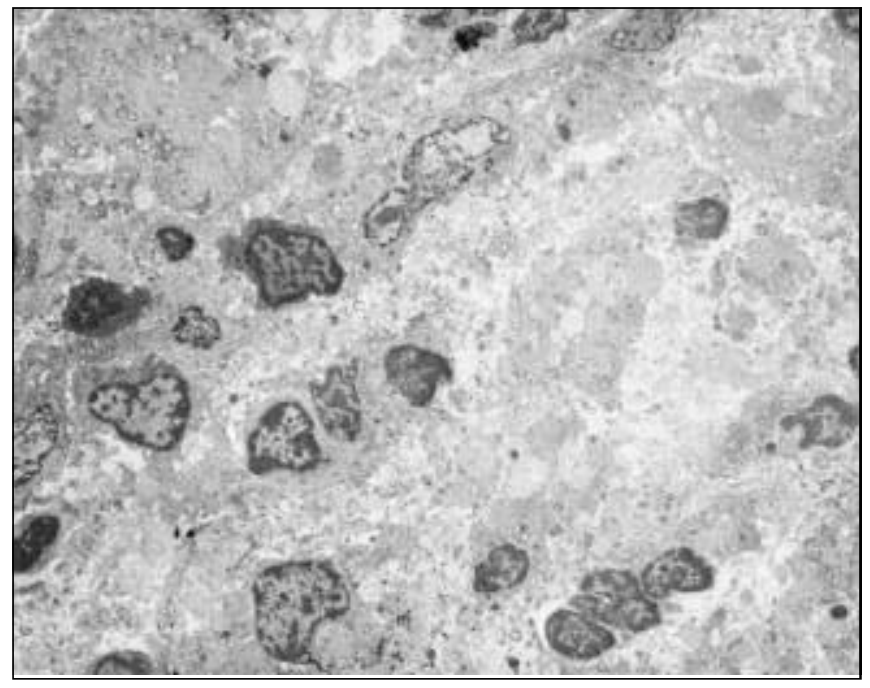

Figura 3: Infiltração inflamatória sem predomínio celular específico na lâmina própria (2000X).

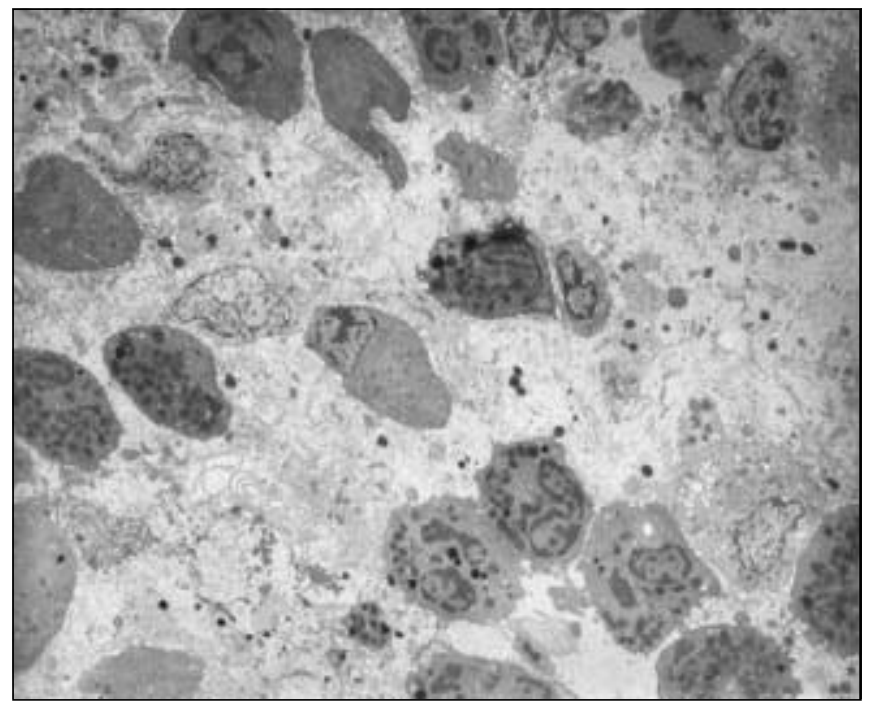

Figura 5: Lâmina própria com grande população de eosinófilos (2000X).

\section{Caso 9}

Processo inflamatório desorganizado (anárquico): Aqui o quadro misto apresenta um discreto predomínio do processo alérgico sobre o inflamatório. Os plasmócitos destacam-se dentre a população celular (Figura 9).

\section{Caso 10}

Processo inflamatório desorganizado (anárquico): Há uma grande diversidade celular nesse caso, com a lâmina própria rica em macrófagos e fibroblastos. Vemos uma

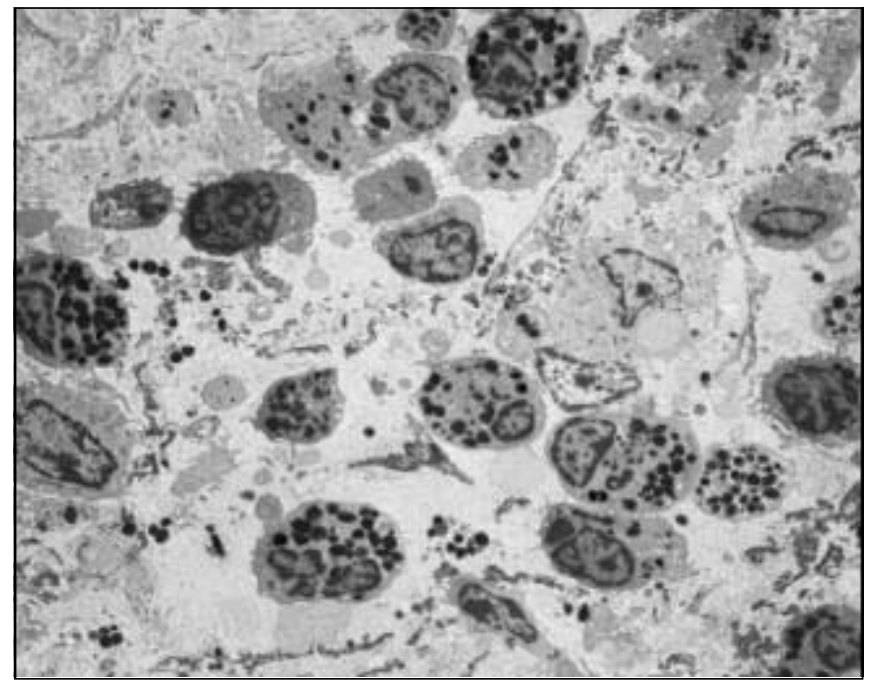

Figura 4: Processo inflamatório agudo com predominância neutrofílica na lâmina própria (2000X).

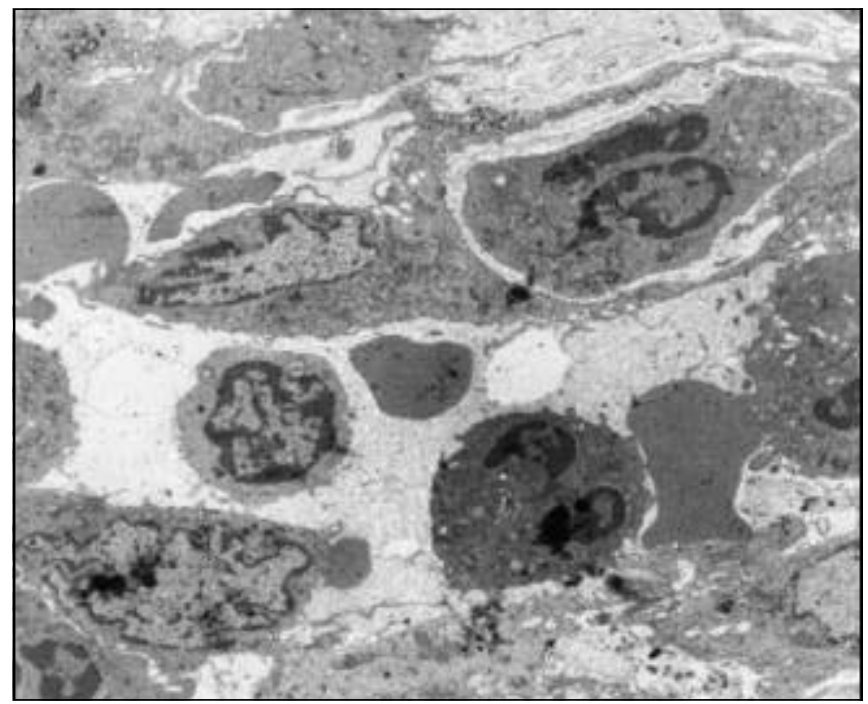

Figura 6: Infiltração inflamatória abundante na lâmina própria, com grande diversidade celular (3200X).

indefinição da substância intercelular.

\section{Caso 11}

Processo inflamatório crônico (resposta tardia): Há uma tendência à organização e fibrose nesse caso, mas com atividade celular presente. Vemos grande quantidade de colágeno no interstício, que apresenta áreas com muitos restos celulares. A destruição celular é maciça, com presença de anarquia entre as células. O bservamos grande diversidade celular e presença de plasmócitos ativados, com leve tendência a um predomínio celular mononuclear. 


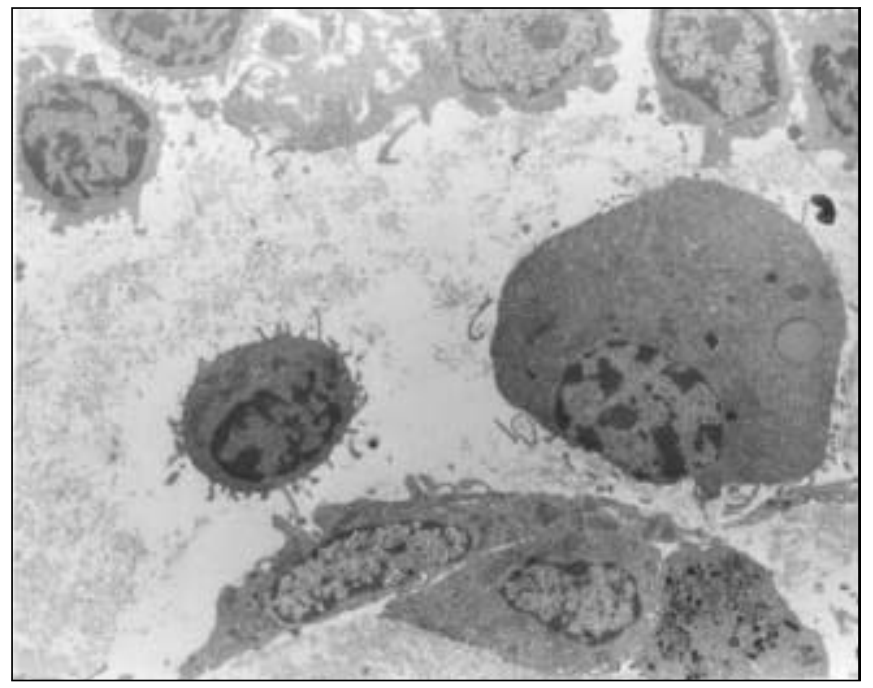

Figura 7: Lâmina própria infiltrada porcélulas inflamatórias diversas (3200x).

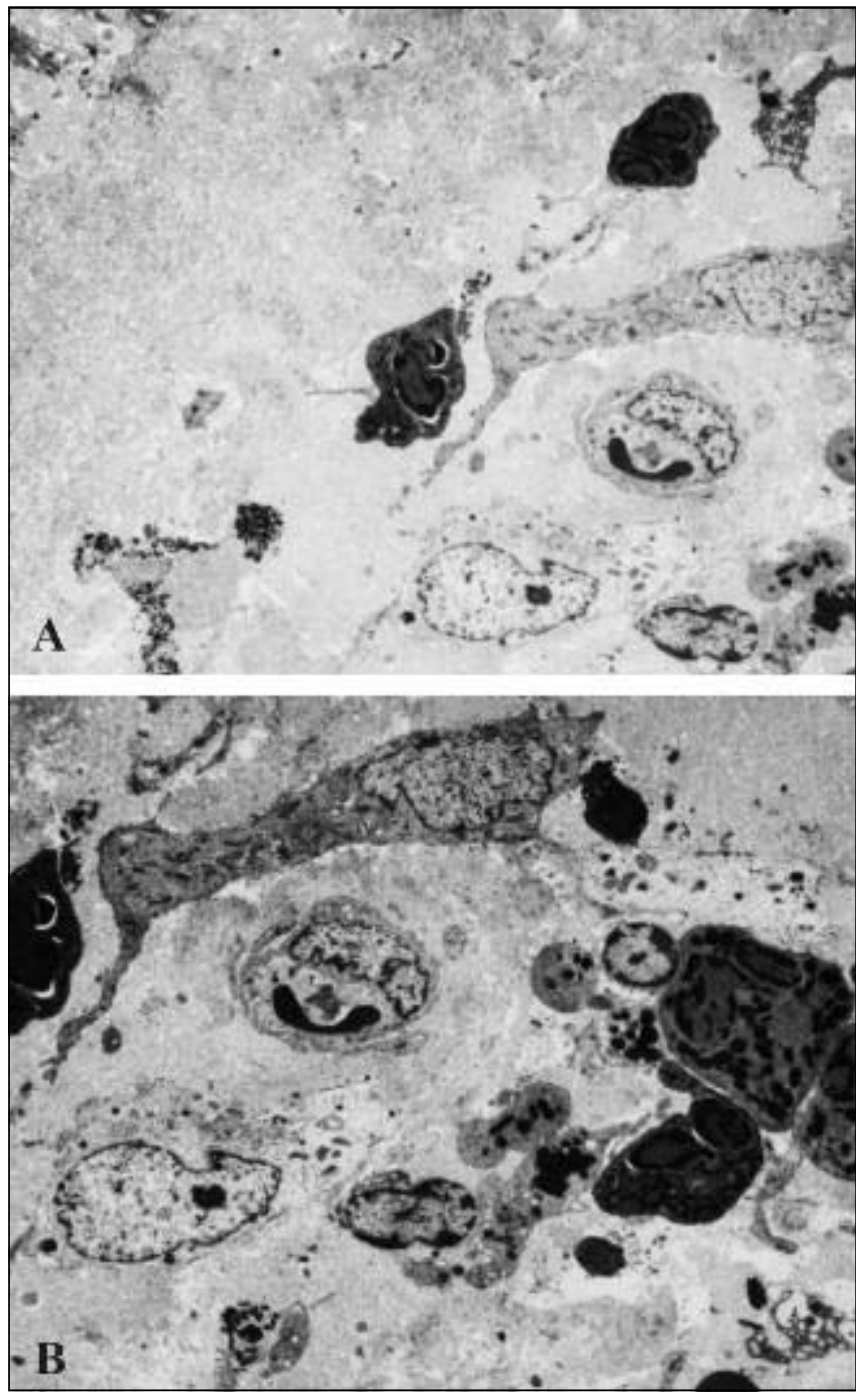

Figura 8: A- Área de fibrose sub-epitelial (2000X). B- Infiltrado inflamatório intenso e diversificado na lâmina própria (2500X).
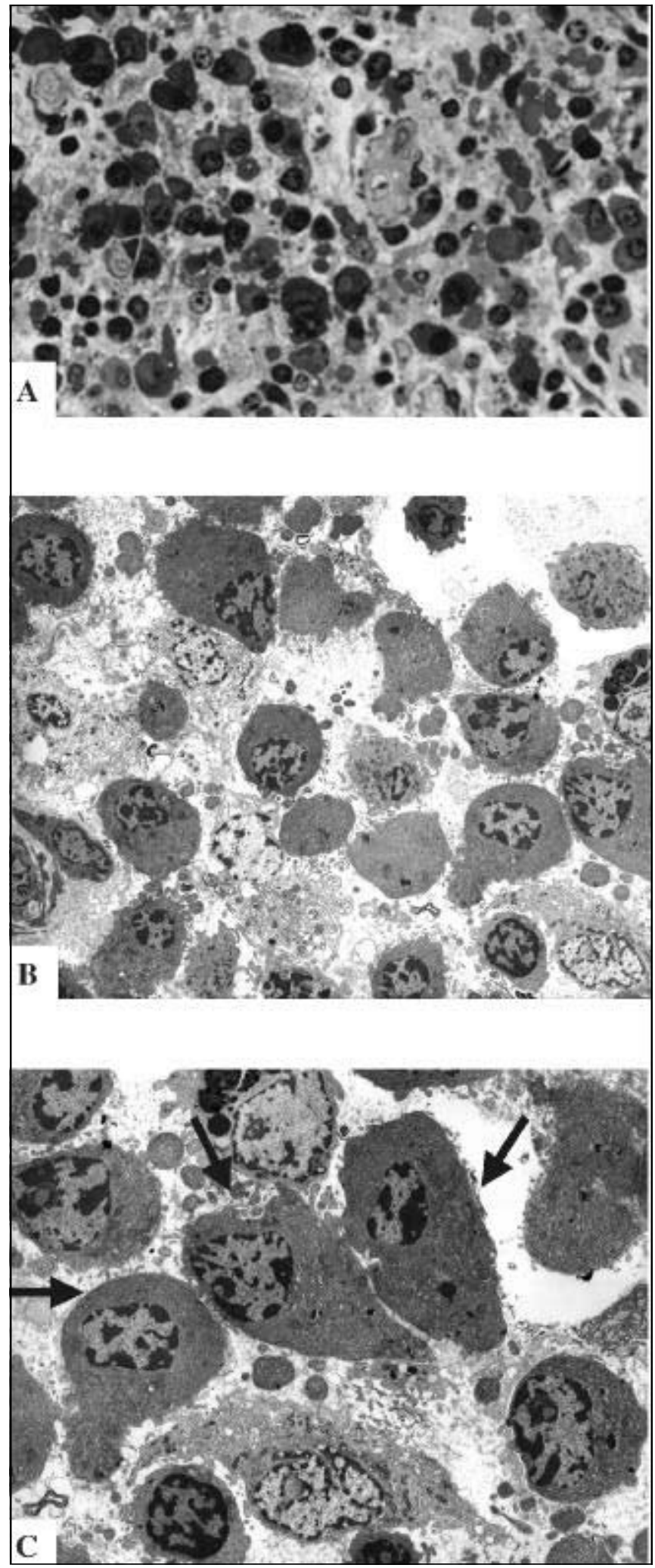

Figura 9: Epitélio respiratório atípico. A- MO: lâmina própria com rica celularidade e predominância de plasmócitos (63X); B- MET: a mesma lâmina mostrando a rica celularidade (2.000X); C - MET: plasmócitos em maior aumento - setas (3.200X) 


\section{Caso 12}

Processo inflamatório não agudo e não crônico: A resposta inflamatória nesse caso é agressiva, com presença de macrófagos, eosinófilos, linfócitos e plasmócitos, nenhum predominando sobre os outros. 0 interstício apresenta restos celulares. Notamos áreas com deposição de colágeno caminhando para a organização e a resolução do processo inflamatório (aspecto mais tardio, crônico do quadro).

\section{Caso 13}

Processo inflamatório desorganizado (anárquico): O bservamos uma desorganização do processo inflamatório com presença de grande diversidade de elementos celulares. Não encontramos nenhuma célula inflamatória predominando sobre as outras. Notamos um quadro misto, onde a resposta inflamatória predomina levemente sobre a resposta alérgica (Figura 10).

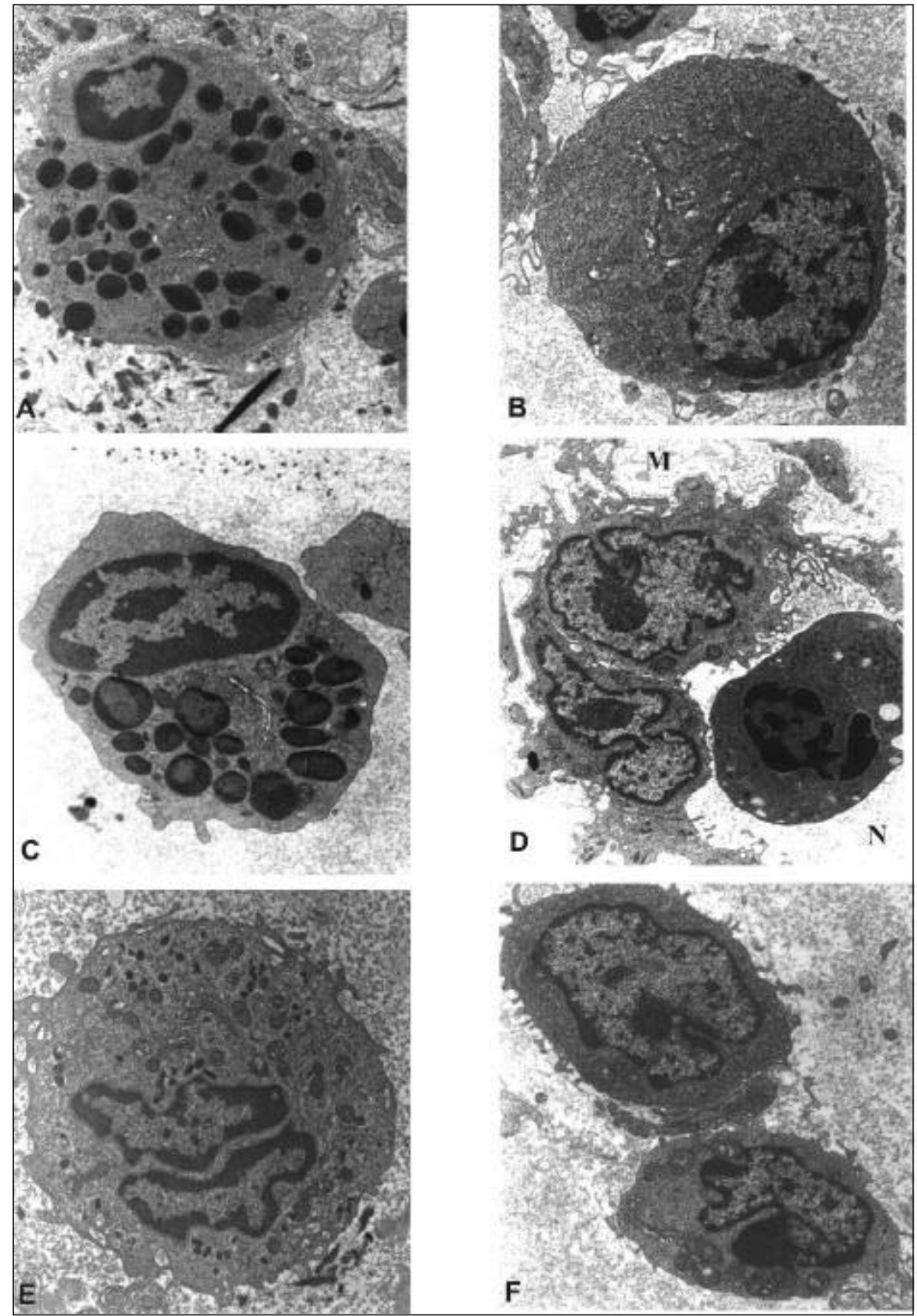

Figura 10: MET: população celular diversificada encontrada na lâmina própria dos pacientes. Aeosinófilo; (6.300X) B- plasmócito; (6.300X). C- mastócito; (10.000X) D- macrófago e neutrófilo (6.300X) (M e N); E- macrófago; (10.000X) F- linfócitos (6.300X). 


\section{DISCUSSÃO}

Diversos fatores estão relacionados com a fisiopatologia da RSC. Muito já se falou sobre as alterações epiteliais e do clearancemucociliar nas RSC, mas pouco se estudou as alterações encontradas na lâmina própria da mucosa sinusal acometida pelo processo inflamatório crônico. Os casos que serviram como grupo controle apresentaram um lâmina própria fina, como descrita nos tratados da literatura, completamente diferente dos pacientes, nos quais observamos cinco tipos de resposta inflamatória. Processo inflamatório agudo - 1 caso; processo inflamatório não agudo e não crônico - 5 casos; processo inflamatório crônico - 2 casos; processo inflamatório desorganizado - 4 casos; processo inflamatório indeterminado - 1 caso. Os dois tipos mais freqüentes de resposta, o processo inflamatório não agudo e não crônico e o processo inflamatório desorganizado, apesar de classificados separadamente, apresentam semelhanças entre si: grande diversidade de elementos celulares, sem predomínio de nenhuma série celular. Na maioria das vezes, observamos elementos de fase aguda e de fase crônica associados. No processo não agudo e não crônico, geralmente há uma discrepância entre as respostas do interstício e da celularidade quanto à fase (aguda ou crônica) da inflamação. Já no processo desorganizado, além da diversidade de elementos agudos e crônicos, vemos também uma combinação não esperada entre os representantes das respostas inflamatórias alérgica e não alérgica.

Nos casos em que vemos um processo inflamatório não agudo e não crônico, há uma tendência à cronicidade e resolução do quadro inflamatório. Já nos casos classificados como processo inflamatório desorganizado, há uma grande indefinição do quadro.

Os dois casos que mostram processo inflamatório crônico apresentam evidentes sinais indicativos de resolução do quadro. A resposta inflamatória aparentemente evolui dentro do esperado, com base na seqüência de eventos do processo inflamatório. Também mostram abundância celular (celularidade do quadro crônico, tendência à predomínio mononuclear), mas o processo é organizado e vemos fibrose nos dois casos.

Classificamos um dos casos como processo inflamatório agudo devido à predominância neutrofílica do infiltrado celular. Essas células são geralmente associadas à inflamação aguda ${ }^{1,4}$. Muitos autores falam em diversos tipos de alterações histológicas nas RSC e a predominância de neutrófilos pode se encaixar em um desses tipos.

0 caso tido como processo inflamatório indeterminado foi de difícil classificação, visto que em um mesmo paciente pudemos observar quadros histológicos distintos lado a lado, nenhum predominando sobre os outros ${ }^{5}$.

Glândulas na lâmina pró pria não foram observadas por nós em nenhum dos casos, provavelmente devido ao fato da localização da biópsia no seio maxilar (parede súpero- lateral ser uma região normalmente desprovida de glândulas), que nesse seio em particular costumam ser encontradas apenas ao redor de seu óstio natural ${ }^{6,7}$.

Enfatizando a celularidade da lâmina própria do seio maxilar nesses casos de RSC, podemos dizer que o nosso achado evidente de grande diversidade de elementos celulares concorda com a literatura mundial. De um modo geral, fala-se em um predomínio de leucócitos mononucleares, mas sempre com presença dos granulócitos polimorfonucleares. Tos \& Mogensen (1984) ${ }^{8}$ estudaram histologicamente 47 amostras de seio maxilar de 38 pacientes com RSC e encontraram em todos os casos, graus variados de infiltração por linfócitos e plasmócitos. Em poucos pacientes uma grande infiltração leucocitária foi o achado predominante na lâmina própria, enquanto outros apresentavam infiltrado eosinofílico. Comparando esse estudo com os nossos dados, notamos infiltração leucocitária como principal achado histopatológico da lâmina própria em muitos e não em poucos pacientes. Essa infiltração celular, em 7 dos nossos 13 casos (53.84\%), mostrou grande diversidade celular, com graus variados de infiltração por linfócitos e plasmócitos (assim como os pacientes de Tos \& Mogensen). Um infiltrado predominantemente eosinofílico foi visto em apenas um dos nossos casos (7.69\%).

Um grande aumento no número de células inflamatórias na lâmina própria foi visto em todos os pacientes estudados por Stierna \& Carlsö ö ${ }^{5}$, (1990). Estas células eram principalmente linfócitos, plasmócitos e ocasionalmente granulócitos polimorfonucleares, o que indicava a natureza crônica da resposta inflamatória. Nossos dados concordam em parte com os anteriores. Também notamos grande infiltração celular, mas não conseguimos distinguir células predominantes na maioria deles (53.84\%). Os plasmócitos e os polimorfonucleares foram as células predominantes, cada um em um de nossos casos; também tendo sido células citadas pelos autores acima.

Nesse estudo, estabeleceu-se uma relação direta entre a intensidade da infiltração celular com a intensidade do edema da lâmina própria. 0 espessamento subepitelial (interpretado como hialinização da membrana basal) associase freqüentemente a um aumento do número de eosinófilos. Em nossos casos, não notamos essa associação.

Em seu estudo, Forsgreen et al. ${ }^{6}$ (1993) encontraram os linfócitos e monócitos como as células inflamatórias predominantes no infiltrado, embora granulócitos polimorfonucleares (como neutrófilos e eosinófilos) também foram detectados. Também detectamos polimorfonucleares, mas não reproduzimos o achado de predomínio mononuclear, visto por nós em apenas dois casos (15.38\%). Assim como Stierna $\&$ Carlsö ${ }^{5}$, (1990), esses autores notaram que o espessamento da mucosa (subepitelial) está intimamente relacionado com a quantidade de células inflamatórias.

Demoly et al. (1998) ${ }^{9}$ encontraram uma mucosa sinusal infiltrada por eosinófilos, mastócitos, macrófagos e 
linfócitos. Não houve diferença entre esses dois grupos analisando-se a infiltração por eosinófilos ativados e macrófagos, mas observou-se aumento do número de linfócitos T e mastócitos intraepiteliais no grupo dos atópicos. Com base no estudo acima, podemos dizer que nem sempre a alergia é a responsável pela eosinofilia do infiltrado celular nas RSC, o que pode justificar o achado incompatível de presença de elementos do processo inflamatório e do processo alérgico juntos, como em alguns dos nossos casos classificados como processo inflamatório desorganizado.

Ghaffar et al. (1998) ${ }^{10}$, afirmam que estudos prévios já haviam demonstrado dois mecanismos distintos envolvidos com a eosinofilia tecidual nas RSC. Na mucosa sinusal de pacientes com atopia, 0 aumento do RNAm para IL-4 e IL-5 foi potencialmente envolvido com 0 aumento de eosinófilos no tecido. Já a elevada expressão do RNAm para GM-CSF e IL-3, foi correlacionado com a densidade de eosinófilos teciduais em pacientes portadores de RSC alérgica e não alérgica. Lee et al.(1998) ${ }^{11}$, através de seu estudo, também afirmam que existem mecanismos distintos de eosinofilia em pacientes alérgicos e não alérgicos.

Resumindo, notamos uma diversidade muito grande de elementos celulares em todos os casos, sem predominância de nenhum tipo celular do processo inflamatório sobre os outros na maioria deles sete em treze, ou $53.85 \%$. Em dois casos ( $15.39 \%$ ) houve predomínio mononuclear; em um caso, predomínio neutrofílico (7.69\%); em um caso, predomínio de eosinófilos (7.69\%); em um caso, predomínio de plasmócitos (7.69\%); e no último caso, predomínio de macrófagos (7.69\%).

A organização do interstício e a presença ou não de fibrose na lâmina própria de seio maxilar dos pacientes com RSC mostra-nos se o quadro inflamatório ten de a caminhar para a resolução do processo.

A população de monócitos e macrófagos é essencial para a reparação do tecido normal e das células remanescentes no sítio da ferida, por al guns dias ou até semanas. $\mathrm{Na}$ mucosa sinusal cronicamente inflamada a ativação contínua de células mononucleares promove proliferação de fibroblastos e o desenvolvimento de fibrose. Pela ação das citocinas secretadas, os monócitos e macrófagos participam no debridamento, processos microbicidas e coordenação dos eventos envolvidos na reparação tecidual ${ }^{12}$.

No estudo de Ghaffar et al. (1998) ${ }^{10}$, já citado por nós, os autores colocam os mastócitos, juntamente com os eosinófilos, como principais produtores de IL-6. Tanto a expressão epitelial quanto subepitelial da IL-6, nesse estudo, foi maior em pacientes com RSC associada à PNS, que no grupo controle. Não houve diferença entre os pacientes alérgicos e não alérgicos, pois a produção de IL-6 pelos mastócitos independe do fenômeno de degranulação dos mesmos. A produção de IL-6 é induzida por IL-3, GM-CSF e por lipopolissacarídeos bacterianos. Essa citocina foi colocada como indutora da proliferação de fibroblastos, da deposi- ção de colágeno e da diminuição da quebra de colágeno. Todas essas ações contribuem para a formação de fibrose.

Em nosso estudo, embora o número de casos não nos permita chegar a uma conclusão definitiva, notamos que a fibrose é mais presente nos casos com maior organização do interstício e com tendência à resolução do processo.

Nos casos classificados como processo inflamatório desorganizado não notamos fibrose em nenhum dos pacientes, sem nenhum sinal de resolução do processo. Talvez esses casos sejam aqueles que não conseguem evoluir para cura, independente do tratamento adequado. Para chegarmos a tal conclusão, precisamos dar continuidade a esse estudo no futuro, fazendo controles histológicos pós-operatórios. Já nos casos classificados como processo inflamatório crônico, a fibrose estava presente nos dois pacientes estudados, em associação com um infiltrado predominantemente mononuclear, mostrando uma nítida tendência à organização do interstício e resolução do processo inflamatório.

Dos cinco casos classificados como processo inflamatório não agudo e não crônico, três biópsias mostravam presença de fibrose na lâmina própria do seio maxilar. Esses casos já mostram certa tendência à resolução do quadro, embora ainda com indefinição da celularidade do processo inflamatório. No paciente com predomínio de celularidade neutrofílica, observamos fibrose discreta, o que é condizente com a presença escassa de monócitos, macrófagos e eosinófilos.

Em al guns dos nossos casos, mais claramente no caso 1 e no caso 8, notamos que a fibrose se localiza na área da lâmina própria mais próxima do epitélio, na região da membrana basal. Segundo Forsgren et al. (1996) ${ }^{12}$, o espessamento da membrana basal reflete um aumento na deposição de colágeno abaixo da membrana basal normal e é comum em situações patológicas nas quais as células epiteliais que se apóiam na membrana apresentam processos acelerados de esfoliação e renovação celular. Esse espessamento é visto mais freqüentemente em pacientes asmáticos e/ou atópicos, o que condiz com a observação de Stierna \& Carlsöö, $(1990)^{5}$ de que o espessamento subepitelial é um achado muito associado com um aumento de eosinófilos, célula relacionada com quadros alérgicos. Esses autores interpretam esse espessamento também como uma hialinização da membrana basal. Vale ressaltar que nos nossos casos 1 e 8, onde vemos fibrose subepitelial, não temos predomínio eosinofílico.

As alterações teciduais observadas nas RSC são consistentes com a atividade biológica dos mediado res químicos derivados das células inflamatórias. Talvez esteja aí a chave para o entendimento da desorganização do processo inflamatório em alguns pacientes com RSC, o que poderia explicar a dificuldade de cura definitiva do quadro, mesmo com a terap êutica adequada (inclusive tratamento cirúrgico). A regulação da organização dos eventos do processo inflamatório é essencial para a resolução do mesmo, seja 
através da reparação do tecido normal, seja através de um processo de cicatrização. Analisando os casos estudados por nós, observamos na maioria dos pacientes (nove em treze $69,23 \%$ ) uma desorganização do quadro inflamatório.

Alguns autores chamam a atenção para o conceito da hipótese de diferenciação do microambiente na inflamação da via aérea nasal ${ }^{13,14}$. Esses estudos podem e devem ser correlacionados com estudos em mucosa sinusal cronicamente inflamada. 0 mecanismo de regulação do processo inflamatóno tanto nas mucosas rinossinusais com inflamação crônica quanto nos pólipos nasais deve ser semel hante, visto que essas patologias associam-se com muita freqüência. Muitos autores colocam a inflamação crônica da mucosa nasossinusal como o principal fator associado à formação de lesões polipóides ${ }^{14-16}$. Existem algumas evidências de que esta hipótese do microambiente da inflamação da via aérea está sob algum tipo de controle genético, sistemicamente, ou ao nível da própria via aérea nasal. Estando as citocinas intimamente relacionadas com a regulação do processo inflamatório, provavelmente são elas que devem estar sob esta regulação genética, interferindo com a evolução do quadro inflamatório nasossinusal.

0 estudo do processo inflamatório na lâmina própria dos seios afetados pela inflamação crônica, a nosso ver, servirá para nortear estudos posterio res correlacionando 0 aspecto dos sinais inflamatórios com o nível de expressão de cito cinas e com a evolução do quadro, tanto histológico quanto molecular, após o tratamento. Partindo daí, poderemos melhorar o nosso entendimento da evolução de todo o processo, talvez permitindo intervenção em alguma etapa, com a finalidade de resolução do quadro.

\section{CONCLUSÕES}

1) A lâmina própria do seio maxilar dos pacientes estudados encontrou-se ocupada por uma infiltração aumentada de células inflamatórias, sem predomínio específico de um elemento celular sobre os outros. Não observamoselementos glandulares na lâmina própria do seio maxilar de nenhum dos casos, e a fibrose foi notada em quase metade dos casos, de intensidade leve a moderada, algumas vezes preferencialmente localizada logo abaixo do epitélio.

2) A maioria dos nossos casos mostrou uma desorganização marcante do processo inflamatório na lâmina própria dos seios maxilares. Na situação vista, o processo inflamatório não seguiu as etapas normais de evolução, mostrando dificuldade em caminhar até a resolução do quadro.

\section{REFERÊNCIASBIBLIOGRÁFICAS}

1. Pereira FEL, Bogliolo L. Inflamações. In: Brasileiro Filho G, ed. Patologia geral. Rio de Janeiro, Guanabara, 1993. Cap. 7, p. 111143

2. Bambirra EA, Paulino UUHM, Tafuri WL, Pereira FEL, Bogliolo L, Pereira FEL. Noções de imunopatologia. In: Brasileiro Filho G, ed. Patologia geral. Rio de Janeiro, Guanabara, 1993. Cap. 9, p. 186-208.

3. Pereira FEL. Etiopatogênese geral das doenças. In: Brasileiro FiIho G, ed. Patologia geral. Rio de Janeiro, Guanabara, 1993. Cap. 3, p. 19-44.

4. Rudack C, Stoll W, Bachert C. Cytokines in nasal polyposis, acute and chronic sinusitis. American Journal of Rhinology 1998; 12(6):383-8.

5. Stierna P, Carlsöö B. Histopathological observations in chronic maxillary sinusitis. Acta Otolaryngol Stockholm 1990; 110:450-8.

6. Forsgren K, Stierna P, Kumlien J, Carsöö B. Regeneration of maxillary sinus mucosa following surgical removal. Ann Otol Rhinol Laryngol 1993; 102:459-66.

7. Edelstein DR Bushkin SC. Applied nasal physiology. In: Anand K, Panje WR. eds. Practical endoscopic sinus surgery. New York: McGraw-Hill; 1993. p. 18-9.

8. Tos M, Mogensen C. Mucus production in chronic maxillary sinusitis. Acta Otolaryngol, Stockholm 1984; 97:151-9.

9. Demoly P, Crampette L, Lebel B, Campbell AM, Mondain M, Bousquet J. Expression of cyclo-oxygenases 1 and 2 proteins in upper respiratory mucosa. Clinical and Experimental Allergy 1998; 28:278-83

10. Ghaffar $O$, Lavigne F, Kamil A, Renzi P, Hamid Q. Interleukin-6 expression in chronic sinusitis: Colocalization of gene transcripts to eosinophils, macrophages, T lymphocytes, and mast cells. Otolaryngology-Head and Neck Surgery 1998; 118(4):504-11.

11. Lee $\mathrm{CH}$, Rhee C-S, Min Y-G. Cytokine gene expression in nasal polyps. Ann Otol Rhinol Laryngol 1998; 107:665-70.

12. Forsgren K, Fukami M, Penttilä M, Kumlien J, Stierna P. Endoscopic and Caldwell-Luc approaches in chronic maxillary sinusitis: A comparative histopathologic study on preoperative and postoperative mucosal morfology. Ann Otol Rhinol Laryngol 1996; 104:350-7.

13. Allen JS, Eisma R, La Freniere D, Leonard G, Kreutzer D. Characterization of the eosinophil chemokine rantes in nasal polyps. Ann Otol Rhinol Laryngol 1998; 107:416-20.

14. Bernstein JM, Gorfien J, Noble B. Role of allergy in nasal polyposis: A review. Otolaryngology-Head and Neck Surgery 1995; 113:72432.

15. Davidsson A, Danielsen A, Viale G, Olofsson J, Dell'orto $P$, Pellegrini C, Karlsson MG, Hellquist HB. Positive identification In Situ of mRNA expression of IL-6, and IL-12, and the chemotactic cytokine RANTES in patients with chronic sinusitis and polypoid disease. Acta Otolaryngol, Stockholm 1996; 116:604-10.

16. Park H-S, Kim H-Y, Nahm D-H, Park K, Suh K-S, Yim H-E. The presence of atopy does not determine the type of cellular infiltrate in nasal polyps. Allergy and Asthma Proc 1998; 19:373-7. 